\title{
Pain, Private Language and the Mind-Body Problem
}

JAMES ANDERSON

University of Pennsyluania

What I will call the Warner-Nagel thesis is the claim that, even with a true and exhaustive scientific description of the world, we will have falled to capture a fundamental and important aspect of it: the qualitative character of experience. of the two, Nagel's thesis is stronger. For he claims that objective science cannot capture the gualitative character of our experience ("facts of experience") because science moves away from facts which are accessible from only one point of view, and towards facts which are intersubjective or public.' Since understanding what it is like to be an $x$, requires facts which are accessible from only one point of view, $X ' s$, the methodology of science is simply unsuited for the sort of understanding required to capture the qualitative character of a thing's experiences. Hence reductionist programs were 111 conceived from the very beginning: there is something about consciousness that cannot be captured in scientific accounts of the mind.

Warner' 8 argument does not have this ring of finality about it. He concedes, for instance, that "some as yet unformulated form of physicalism might be true" and concentrates his argument on current electrochemical theories of the brain (and thus remains silent as to the Inherent limitations of objective science).? Warner admits, however, that in so doing he concedes little. His thesis is clearly that science, as far as we are capable of conceiving $i t$, cannot capture the gualitative character of experience; and thus property dualism is the correct philosophical analysis of mental states.

In what follows I will concentrate upon Warner's paper "In Defence of a Dual $1 \mathrm{sm}$ " and mention Nagel's arguments only as they bear upon the issues considered. Since, as of this writing, Richard Warner's paper remains unpublished, (though widely circulated and read), no familiarity with the paper will be assumed on the part of the reader.' In rough outline, section 1 of this paper detalls Warner's argument for the WarnerNagel thesis. Section 2 briefly discusses the logical relation between Warner's argument and Nagel's wellknown argument in "What is it like to be a Bat.". 
Section 3 contains direct critlcisms of Warner's argument. Section 4 outlines what I take to be wrong with any account of property dualism, and section 5 suggests relations between the Warner-Nagel thesis and private language. Reference 18 here made to Kripke's Wittgenstein: On Rules and Private Language.

I should begin by saying that, for the most part, I agree with the Warner-Nagel thesis. I do not believe that physicalist or functionalist theories of the mind capture the qualitative character of our experiences; nor do I think they can. I do not believe, however, that Warner's argument establishes this claim. And, most importantly. I do not believe this limitation on physicalism implies that we should accept either property or substance dualism. I will, of course, say a good deal about this later, but the thought behind this assertion is the following. To understand what it is like to be an $X$ requires that one instantiate a certain physical or functional state. But this state is not the state which it is like to be in when one, e.g.. reads about an $x$ or studies an $x$. Warner and Nagel understand this distinction when they tell us that reading about pain (or bats) falls to help us understand what it is like to be in pain (or be a bat). It is natural to say at this point that of course the two are different, and why should this discrepancy constitute a lack of knowledge? After all, we may study black holes or electrons without being black holes or electrons.

As natural as this rejoinder may be, it misses the point of Warner's and Nagel's argument. Their point is that it 18 not like anything to be a black hole or electron, whereas it is like something to be in pain or a bat. Therefore our scientific accounts of the world would fall to capture an important aspect of the world in the case of consciousness, which they would not fail to capture in the case of inanimate objects. With a true and complete theory of black holes, for instance, there would be nothing left to know about black holes. The same is not true of pain; with a true and complete theory of pain there would be something left to know about pain: how it feels.

Having conceded this point to Warner and Nagel, however, I do not think we are logically forced to concede that the only analysis of mind is property dualism. One of the arguments presented later in the paper will be a refined version of the unsatisfactory rejoinder mentioned above. It is a contingent fact about me that I can only instantiate a limited range of states. The states I can instantiate are physical ones; my seeing red is a functional state which I can know what it is like to be in because I have instantiated the appropriate physical state." And the reason a color bilnd 
person cannot know what it is like to see red is not because the physical theory somehow fails, but rather because understanding a true and complete theory is not the same as instantiating the state of seeing red. What is wrong with the color blind individual has nothing to do with his ability to understand a theory; it has to do with his inability to instantiate a physical state. Nagel's facts of experience, if indeed they are facts at a11, do not point to fallures in theory but to limitations in the contingent range of physical states one can instantiate. At this point, however, it is probably best to present Warner's argument and take up these matters once the Warner-Nagel thesis has been argued for.

Warner's argument proceeds as follows. It is an empirical fact that there are people congenitally unable to feel pain. Such a person Warner refers to as painless. The argument then is

(1) If pain is Identical with an electrochemical state, then a painless person could acquire the ability to know nonevidentially that he is in pain; he could acquire this ability while remaining painless.

(2) One can acquire the ability to know nonevidentially that one is in pain only if one can feel pain.

(3) Therefore, pain cannot be identical with an electrochemical or functional state.

What Warner means by nonevidential is (1) there are cases where a person feels pain, or is in pain, and (2) no evidence other than the pain 1 tself needs to be considered for a person to know that he $1 \mathrm{~s}$ in pain. Evidence for being in pain would be appropriate if it were possible that one should seem to be in pain when one is in fact not. Here Warner assumes that "pain has a certain 'qualitative character'--a certain felt quality-which manifests itself to one who feels pain. This qualitative character is such that if it seems to be present, it is present; and if it is present, one is in pain."

Why accept premise (1)? We imagine that the painless person first reads and understands the electrochemical theory $T$ which describes the state $S$ which (the identity theorist claims) is identical to feeling pain. He learns that the electrochemical state $s$ is pain. But "this is not all he learns, for he reads a complete and true description of pain--that is, $s$. Nothing is left out." In particular, he reads a description of the way pain feels. Warner's claim in premise (1). then, is that if the identity theory (or physicalism, or functionaîsm) is true, the painless 
person who reads and understands the complete and true description will acquire the ability to know, nonevidentially, that he is in pain. This, Warner argues, has counterfactual content. If a painless person were, after reading the theory, to feel pain, he could--even for the first time--know nonevidentially that he was in pain. Warner argues for the truth of (1) by arguing for the truth of this counterfactual.

His argument $1 \mathrm{~s}$ this. We suppose that a painless (and curious) Alpha Centaurian temporarily modifies his central nervous system in order to induce $s$ (a mild, but painful stomach cramp) in himself. "The experimenter gives the nod to his assistant to flip the switch and Immediately after that he simultaneously experiences nausea and a mild, but painful stomach cramp. The nausea was an unforeseen consequence of the alterations in his nervous system. " If the identity theory is true, the Alpha Centaurian must know, nonevident1ally. which of the two is pain. He has a complete and true description of pain, even the way pain feels, so how can he fall to know which of the two feelings is pain? To say that he must know nonevidentially which of the two is pain simply means that he cannot check his instruments, or any other evidence other than the qualitative way in which each sensation feels, in deciding which of the two is pain.

The truth of the counterfactual, then, rests upon three assumptions. (A) T states everything there is to state about pain. (B) The qualitative character of pain manifests 1 tself nonevidentially. And (C), from $T$ the Alpha Centaurian acquires the recognitional abilities necessary for correctly identifying the qualitative character of pain. Thus, if the identity theory is true, premise (1) is true.

I will return to these assumptions shortly. But first, how is premise (2) established? Warner doesn't argue for (2) directly; rather, he argues for the falsity of the consequent of (1). Of course this would directly establish that pain is not an electrochemical state, but Warner thinks that (2) "1s important; it $18, "$ he suggests, "the best explanation of why the consequent of (1) is false." (The logical inference in the argument is modus tollens.)

Warner's argument for the falsity of the consequent of (1) is simple and direct. Pain manifests itself as having a certain qualitative character which the Alpha Centaurian will be ignorant of until he has the appropriate sort of experience. But he cannot know nonevidentially which of the two experiences (pain or nausea) is the one which he set out to induce in himself until he checks his instruments. He cannot know nonevidentially that the relevant electrochemical activity is occurring. The electrochemical description of pain which he has read and understood $1 \mathrm{~s}$ the only thing about pain that could possibly play a role in his nonevidentially 
knowing that he is in pain. But pain does not manifest 1 tself to a pain feeler as such-and-such electrochemical activity; and in order to acquire this knowledge (1.e. knowledge of the electrochemical state he is in) he must, of course, check his instruments. Indeed, there is no reason to believe that, until he checks his instruments, he will belleve either feeling to be pain. Thus the consequent of (1) is false.

I belleve this argument is quite correct; the Alpha Centaurian cannot teli which feeling is pain by virtue of his knowledge of $T$. Consider a congenitally blind person. With knowledge of a true and complete theory $C$ for colors, the visual spectrum, optics and even such Information as "Red looks like what a trumpet sounds like," there is no reason whatsoever to belleve that the congenitally blind person could distinguish red from purple immediately following corrective surgery. I believe the reason in both cases is that neither the painless individual nor the congenitally blind individual has the necessary background of recognitional abilities needed to make the relevant distinctions. So, if we are to resist Warner's conclusion, it must be through refecting one or more of the assumptions made in establishing premise (1).

The crucial assumption used in establishing (1) is (C): From $T$ the Alpha Centaurian acquires the recognitional abilities necessary for correctly identifying the qualitative character of pain. (Recali, the reasoning here, according to Warner, is that the identity theory states that pain is an electrochemical state, $T$ states everything there is to state concerning the electrochemical state of being in pain, so the Alpha Centaurian knows everything there is to know about pain.)

But, as Warner realizes, there seems to be an obvious objection to this. Isn't the ability to know nonevidentially that one is in pain a recognitional ability that no amount of information by itgelf will allow a suitably inexperienced person to havé? Warner uses a person who has never seen a pomegranate to dramatize this point.

Suppose a person who has never seen, say, a pomegranate possesses a true and complete description of pomegranates--including a description of the way pomegranates appear to a normal perceiver. Suppose we place a pomegranate and a nectarine in front of the person, who as it happens has never seen a nectarine. There is nothing defective in the person's perceptual and reasoning faculties: - . It follows that he must be able to tell which is the pomegranate. 10

The relevant information will allow him to know which fruit is the pomegranate--but only if he already pos- 
sesses certain other recognitional abilities: e.g., the ability to recognize dark red. Given these preexisting abilities, he will be able to distinguish the pomegranate from the nectarine. The disanalogy between this and the Alpha Centaurian case is that the latter. by virtue of his previous painlessness, does not have the preexisting background of recognitional abilities. Warner's reply is that the Alpha Centaurian does not lack the necessary background of recognitional abilities. We suppose that the Alpha Centaurian has the ability to know nonevidentially that he has a nonpainful cramping feeling. When he reads $T$ he learns that a cramping feeling of such-and-such intensity is a case of pain--where the degree of intensity is truly and completely described. Even the way such intensity feels is described. "Now how can we deny that the Alpha Centaurian lacks the relevant recognitional abilities because he has never experienced a cramping feeling of the relevant degree of intensity. . . . A person who has never seen a pomegranate may never have experienced the precise color and shape that confront him when he sees his first pomegranate."I And this does not prevent him from recognizing a pomegranate when confronted with one. Thus, according to Warner's reasoning, assumption (C) should be accepted.

\section{II}

In outline at least, this is Warner's argument for the thesis that there is something that cannot be captured in materialist theories of the mind; and therefore, that property dualism is the correct analysis of mental states. It is important to point out that Warner's argument is oufficiently general (both in the scope of his premises and in the nature of his conclusion) as to logically imply Nagel's thesis mentioned above. Warner's argument rests essentially on the assumptions that pain does not manifest itself to pain feelers as electrochemical activity, and that it is possible to know nonevidentially that one is in pain. As Warner remarks, similar facts hold of all nonintentional bodily and perceptual states. If this is so, then we would expect Nagel's 'facts of experience' to be the sorts of things which can be known nonevidentially, and nonelectrochemically. And indeed this seems to be the case. I can know what it is like to be in state $s$ only by at one time or another being in state $S$; and if $S$ is a conscious state--which 1 must be if it is like anything to be in the state--then if I am in 5 I know it. Hence, facts of experience are known nonevidentially. Furthermore, facts of experience are known nonelectrochemically. otherwise, I could know what it is like to be a bat by reading up on the subject. 
Warner goes from facts about what a theory can and cannot capture to the conclusion that consciousness slips through the net of physicalism. There is an essential bit of information or knowledge that the $\mathrm{Alplia}$ Centaurian cannot get from the electrochemical theory: what it is like to feel pain. Nagel, relying on more dubious assumptions, e.g.. 'points of view', argues in similar fashion. What it is like to be an $x$ escapes theoretical explication; hence physicalism cannot be the whole story.

The point of drawing these parallels is to show that successful criticism of Warner is, perforce, successful criticism of Nagel. ${ }^{2}$ With this in mind, I now turn to specific criticisms of Richard Warner's argument.

\section{11}

Does the Alpha Centaurian, then, possess the necessary background of recognitional abilities to know nonevidentially which sensation is pain? I think obviously not. When Warner introduces the possibility that the Alpha Centaurian has experienced nonpainful stomach cramps, (and therefore should possess the required recognitional abilities), he unnecessarily obscures the issue and possibly begs the question. He obscures the issue in that if the Alpha Centaurian has experienced a wide enough range of stomach cramps there is no reason to believe that he shouldn' $t$ be able to recognize the painful stomach cramp. Thus be can no longer truthfully be called painless, which was central to Warner's argument. But if we assume that the Alpha Centaurian, through his previous nonpainful ctamps, has the necessary recognitional abilities, what distinguishes him from the individual who has never seen a pomegranate but yet recognizes one on first viewing? If the Alpha Centaurian possesses the recognitional ablilties, as Warner insists he must, then to assume that he will still be unable to distinguish the two sensations begs the question. We might just as well assume that the pomegranate identification will fail.

Rather than consider examples where the individual almost knows what a painful stomach cramp is, or almost knows what a pomegranate is, we should consider the case of the congenitally blind person who undergoes corrective surgery and is then asked to distinguish red from, say, purple. This is, of course, a variation of Molyneux $s$ question of whether a "man born blind and then made to see" could determine, by sight alone, which of two objects was a cube and which a sphere. Molyneux's question 13 essentially whether there is a necessary connection between the ideas of shape, size, or geometric property afforded by the different modali ties of sight and touch. This is a much more general, and difficuit, question than the one 1 am considering. 
It is worth noting, however, that recent empirical evidence suggests that individuals who have been suitably trained in solid geometry can identify which object is a sphere and which is a cube following corrective surgery." Does the congenitally blind person, then, possess the necessary recognitional abilities to distinguish the two colors? Would a 'colorless' individual have the ability to distinguish one color from another; even assuming that he has the relevant theory of what it is like to see colors in hand?

I think the answer must be an obvious no, he would not be able to distinguish the two colors. visual ablities are insufficiently like tactile or auditory abilities to allow us to acquire knowledge of the perceptual state of seeing a color--1.e.. what it is like to see a color--from information gained from other sense modalities. Even explaining to the colorless person that some colors are cool and others warm will not help; these are simply generalizations based upon contingent correlations which we have discovered through seeing the appropriate colors.

So, should premise (1), or equivalently, assumption (c). be rejected? The realization that the Alpha Centaurian does not have the necessary background of recognitional abilities is probably sufficient for rejecting premise (1). But I think there are even deeper problems with Warner's argument, and it will be instructive to have a look at what these problems are.

In drawing out these problems I shall rely on Nagel's phrase'facts of experience' and mean by it conscious states, or states of which it can truly be said that it is like something to be in. It is like something to see red or feel pain. It is not like anything to be a black hole or rock. Eacts of experience are acquired through experience, not theories. For this reason, Warner and Nagel claim that physicalism cannot capture the essential features of consciousness, or what it is like to be an $x$.

Let us look again at what the painless individual in Warner's example is given. He is given a true and complete theory of pain; nothing is left out. And (all agree) from this alone he cannot distinguish the two sensations. Therefore, the argument goes, physicalism cannot be the whole story. This overlooks a crucial point, however: he is also told what pain feels like. So the claim isn't that from $T$ alone he should be able to distinguish the two sensations if some form of the identity theory is true; rather, the claim is that from $T$ and a description of the way pain feels he should be able to distinguish the two. This is important for the following reason. If we take facts to be the sorts of things capable of being expressed by propositions, then facts of experience should be capable of being expressed by propositions, and indeed they are. I can tell others what my pains are like; I can teil others what 
it is like to be in a certain type of pain. I can even express this to others who haven't experienced exactly the sorts of pains I have. For any bodily or perceptual sensation $S$, if $S$ bears some resemblance relation to $S^{\prime}$, then I can express what $S$ is like in terms of $S^{\prime}$. In order for another to understand what $S$ is like, he either has to have experienced $S$, or $S^{\prime}$. This is what we mean by the necessary background of recognitional abilities. For one who has never experienced a sensation sufficiently like the one I am trying to describe, my description will be meaningless.

So, In describing to the painless person what pain is like, we are, in effect, looking for a $S^{\prime}$ which is sufficiently like what pain is like which will express to the painless person what we mean by pain. Warner's claim that if the identity theory is true the painless person's previous stomach cramps should enable him to know which of the two sensations is pain is actually a claim concerning resemblance relations between stomach cramps and painful stomach cramps. If these are sufficiently alike. then the painless individual should have the necessary background of recognitional abilities. similarly, what the congenitally blind person lacks is access to any $S^{\prime}$ which is sufficiently like the sensation of seeing red which will enable him to understand us when we tell him what seeing red is like.

If the painless person, then, cannot, from $T$ and a description of the way pain feels, distinguish between the two sensations, then it cannot solely be the fault of physicalism, or functionalism, or the identity theory. In fact, it isn't the fault of physicalism at all. We have propositions which express facts of experience. which tell us what it is like to feel pain, see a color, etc. But even with these, the painless person is unable to distinguish the sensations. By Warner's own admission, the electrochemical theory can be of no help: pain doesn't manifest itself as an electrochemical phenomenon to pain feelers. So what the painless person reguires is some resemblance relation between sensations he has experienced and pain. otlierwise. there is simply no way for him to understand what pain is like. (I think this is strikingly clear in the case of the congenitally blind person.)

Adding "If the identity theory is true, then ..." to the argument changes nothing. All that the WarnerNagel thesig really tells us $1 \mathrm{~s}$ that certain aspects of the world will be unintelligible to persons unable to understand the semantics involved in the terms we employ to describe the world. This has as little to do with whether we employ the terms of physicalism as it does with whether we employ only phenomenological terms. It is not the case that when all is said and done, physicalism will have failed to tell us what it is like to be an $x$. Rather, nothing apart from being an $x$, or bearing some relation to $x$, can tell us what 
it 18 like to be an $x$. It is simply a fact about language that we cannot express to the blind person what colors look like, or to the painless person what pain feels like.

To see that the Warner-Nagel thesis cannot simply be a claim about the limits of physicalism vis-a-vis the mind-body problem, consider that even in descriptions of ordinary physical objects we will have no way of expressing to sultably inexperienced individuals what the objects are like. On the level of conscious experience, it is presumably not like anything to be a computer. But we can explain to others what computers are like--they are like Turing machines, or they are like human intelligence, or they are like electronic digital adding machines, etc. But for someone who has no idea what a Turing machine is, or how human intel11gence might by modeled, or what digital adding machines do, these descriptions will be little help. (One can imagine, for instance, the problems an Eskimo would have explaining the proverbial fourteen types of anow to an equatorial dweller.)

I think the general conclusion we can draw from these criticisms of Warner and Nagel 18 that there is, Indeed, a difference between being in a state of paín and reading true and complete descriptions of pain. And the latter yields little knowledge of the qualitative nature of pain. But all this indicates 18 that there is a difference between understanding a description and instantiating a state. It is a contingent fact about us that we can only instantiate a limited number of states. And we cannot know a priori what it will be like to instantiate those states which it is possible for us to be in. To the extent in which this limits our bodily and perceptual sensations, it also limits our knowledge of those states which it can be said that it is like something to be in. But the states we can instantiate are physical ones. If Warner and Nagel insist that, necessarily, our bodily and perceptual states cannot be physical states, then they will have to base this on something more substantial than the contingent fact that we cannot instantiate the same states as a bat.

I now wish to discuss what I take to be wrong with any account of property dualism. While few philosophers seriously consider substance or Cartesian dualism to be a solution to the mind-body problem, property dualism still appears to many a legitimate alternative: particularly in light of the implausibility of eliminative materialism and the failure of logical behaviorism. What I shall argue is that property dualism 18 every bit as conceptually confused as substance dualism; and perhaps even more so since not only do famil- 
lar substance-property problems arise, but even more confounding physical substance, mental property relations arise, which are, so far as I can see, imposstble to make any kind of sense of.

A property dualist will, to some extent, be a reallot concerning mental states. "There are" Warner says, "feelings, thoughts, emotions, and so on, and words like 'pain' refer to such states." Accordingly, the property dualist must say that mental state terms pick out, or refer, to nonphysical properties of physical organisms. There is a problem in even formulating this claim. What does it mean when I say "I have a pain in my finger?" Do we take this as expressing a binary relation between my finger or body and an immaterial 'pain'? Or do we understand the expression as indicating a state of my body which has a nonphysical property? Since no one denies that $I$ am in some physical state, e.g., c-fiber stimulation, when $I$ am in pain, shouldn't the dualist say that it is this state which has the nonphysical property: the 'hur $\mathrm{t}^{\text {or }}$ the pain? But what of my consciousness of the pain? If the pain counts as a nonphysical property, surely my awareness of it must as well. When I use the term 'I' in making first person statements such as "I am aware of a pain," the term 'I' cannot, by the dualist's own reasoning, refer fust to my body. If the 'I'. then, must also refer to a nonphysical property, does this imply that I am a property, that $I$ am a nonphysical property of my physical body?!

There are two replies the dualist might make to these charges. First, he could say that it is an accident of grammar that subject-predicate terms are used in the way in which they are, viz., to distinguish substance-property relations. When I say "I have a pain" I am not referring to a stibstance which has the property of being in pain. Nor when 1 say " 1 am aware of a pain" do I--the dualist--mean to imply that there are two things going on, pain and an awareness. To have a pain is to be aware that one has a pain. Secondly, the property dualist might insist that mental properties are merely concomitant with physical states or events. like c-fiber stimulation, and that this expresses no more than the overall state of the organism, and furthermore that this is no more mysterious than the fact that temperature is a property of a gas which expresses the overall mean kinetic energy of the gas molecules. The first of these replies is at least defensible, but, I think, clearly leads to a Humean bundle-theory of perception and serious problems with self-identity through time. It not only seems natural, but correct. to say that what individuates my perceptions, thoughts, and emotions is the fact that I have them. And it also seems correct to say that the referent of the term 'I" remains the same even though its properties, i.e., mental states, emotions, etc.. change. Thus, it does not 
seem to be a mere 'accident' of grammar that we use subject-predicate terms the way in which we do. It is also not clear that pain and the awareness of pain are one and the same state. If the property dualist wishes to claim this, he is committed to the incorrigibility of first person present tense statements, a doctrine many philosophers would reject.

The real problem in formulating the property dual1st's position, however, arises when wo consider the second claim: that mental properties are somehow concomitant with physical states for events, or properties). Even if we grant that my awareness of my mental states causes the dualist no problems, the relation these mental states, properties, have to my physical body will. The first problem is obviously one of interaction: how do nonphysical properties interact with physical ones? When 1 am aware of pain I physically act in certain ways; I move away from the fire, I seek help and medication, I desire that the pain should cease, and so on. But, according to the property dualist, my desire and awareness are nonphysical properties of my physical body. Thus if they cause me to act in certain ways it seems we have a clear case of a physical substance causally interacting with a nonphysical property. And where there is energy expended and work done, do these nonphysical properties supply these as well? And wouldn't this violate our conservation laws?

All of these objections are familiar enough. My reason for stating them is simply to remind the property dualist that unless he settles for a model where mental states have no causal role whatsoever he w11l face the same problems as the substance dualist. The fact that this is so often overlooked in discussion of the mind requires that these objections be reiterated. What if the dualist continues to insist, however, that mental properties are merely concomitant with physical properties, and that no causal interaction takes place? This fails for two reasons. Elrst, if two predicates are extensionally equivalent, and if the properties which they express are causally indiscernible, I think we should say the predicates express one and the same property. On the dualist's account, the predicates 'pain' and 'c-fiber stimulation' are extenBionally equivalent: where you have one you will have the other. Otherwise he cannot claim that it is the physical property which does the interacting. Where there 18 c-fiber stimulation, there will be pain, and where there is pain, there will be c-fiber stimulation. And it will be the physical state of c-fiber stimulation which causes the pain feeler to act in the way in which he does. Thus the predicates will be extensionally equivalent. Further, the properties they express will be causally indiscernable. The point of saying that the two properties were concomitant was to explain the causal role of the mental property--or better, to 
explain away the causal role of the mental property. It cannot be the case that we will have two distinct properties which are constantly conjoined, as in Putnam's example of the temperature and conductivity of a metal. What leads us to say in the case of temperature and conductivity that we have two properties is the fact that they are causally discernible. Pain, however, unless it is to have a causal role independent of the c-fiber stimulation, will be causally indiscernible from the physical state it is concomitant with. If this convinces us that the two properties are causally indiscernible and that the predicates which express them must be extensionally equivalent, then I can see no reason for not maintaining that the properties are one and the same.

The second problem with this formulation is that most dualist accounts of the mind, at least of the Descartes-Kripke variety, wish to maintain that there is at least a logical possibility that the mind can exist without the body. If mental properties require concomltant physical properties, however, this possibility 18 lost. If pain can exist if and only if c-fiber stimulation exists, then we are faced with saying that there is not even a logically possible world where pain could be associated with another physical process, or no physical process at all. This seems a much too strict logical requirement on any plausible account of dualism: if mental properties are in fact not physical ones, then the logical possibility of their distinct existence should be maintained. As was noted, this account of property dualism fails in this respect.

These difficulties with the dualist's position could be multiplied, but probably to little avail. My point is that however the dualist finally expresses what he means by saying that my pain is a nonphysical property, he will either encounter the same problems as the substance dualist, or find himself defending a position where nonphysical properties are indiscernible from physical ones. In either case, the conceptual and ontological problems seem intractabie.

Finally, I wish to place the issues surrounding the Warner-Nagel thesis in larger perspective. Again, for the sake of argument, assume that the Alpha Centaurian, or the congenitally blind individual, did acquire the recognitional abilities needed to correctly identify pain or color. And they did so simply from reading the theory. What would we be inclined to say about this? 1 think we would have to say that they were privately following a rule. Consider: the Alpha Centaurian certainly feels something, just as the congenitally blind person certainly sees the colors following the corrective surgery. This much no one disputes. The problem 
Is that neither knows how to correctly formulate and apply the concepts necessary to identify the qualitative character of their respective experiences. And, as Warner formulates the problem, the only evidence which they are allowed is the qualitative character of their experiences; they must know nonevidentially which state they are in. So if they were able to correctly formulate and apply the relevant concepts it would have to be privately: consulting others would violate the nonevidential stipulation. And it does no good to claim, at this point, that they are allowed to consult the theory. Everyone agrees that pain does not man1fest itself as an electrochemical phenomenon. If we observed that they were able to formulate the concepts and correctly apply them, we would be forced to say that they were acting independently of the linguistic community. (For this reason, when I say "correctly applying the concepts," I do not mean that they must call red by what we call it. Rather, however they formulate and apply their concepts, their present usage must conform to their past intentions: their behavior must be rule governed.)

As Kripke " formulates the Wittgensteinian sceptical problem which gives rise to the argument against private languages, what we cannot do is point to a fact about our past or present mental states or our external behavior which will guarantee that our present meanings conform to our past intentions. There is nothing in my current or past mental states which determines what I ought to do in the present situation. There is nothing, for instance, which determines that I should not presently mean grue when I say 'green'. The argument against private languages arises when Wittgenstein attempts to meet these sceptical arguments. What Wittgenstein in effect does is replace the question "What must be the case for this sentence to be true? ${ }^{n}$ with: (1) Under what conditions may this form of words be appropriately asserted? And (2), given (1), what is the role, utility, in our lives of our practice of asserting this form of words under these conditions?

What I belleve most philosopherg find compelling and true in this argument is the Idea that, if considered in isolation, the notion of following a rule has no substantive content. Even if we do not accept the claim that there is nothing in our current mental states which determines our present intentions, I think we must still say that following a rule requires public checks upon the conditions in which the rule applies. If we wish to know what Jones means by 'red', we should not look to mental facts about Jones, but rather to the assertablifty conditions under which he says that something is red. This much should be clear: the argument is not that I cannot 'mean' anything I want by a term, or change it as often as I like. The argument, rather, is that the meaning of a term comes only through how it 
is used. And using a term requires public criteria, if the term is used in a rule governed way.

I think this has the following implications for the Warner-Nagel thesis. If premise (1) were true, then the identity theory would imply the pogsibility of a private language. If the Alpha Centaurian could, independently of the linguistic community, formulate and correctly apply pain concepts then we would have a clear case of a rule being followed in isolation from any public checks on the assertability conditions for the term. To say that the Alpha Centaurian lacks the necessary background of recognitional abilities is to say, I would suggest, that not only does he lack the requisite sorts of experiences, but he lacks the requisite sorts of concepts. And if applying a concept requires following a rule, he will never acquire the recognitional abilities nonevidentially.

The private language argument also repudiates the claim that it is the qualitative character of our experience which constitutes our meanings. What constitutes our meanings is how we use terms and the conditions under which we assert them. If this is true, then it is not physicalism, but dualism which implies the possibility of a private langtiage. Nagel and Warner would have us believe that there are mental facts about the world--facts of experience--which necessarily must be nonphysical, and that when we know what it is like to be an $x$, we know something about these facts. In other words, what constitutes the meanings of the terms used to refer to these facts of experience must be what it is qualitatively like to experience them. Hence, we would expect anyone sufficiently acquainted with the qualitative character of say pain, to be able to formulate and apply 'pain' concepts correctly, and do so in the absence of public criteria.

Where, I would suggest, the Warner-Nagel account goes wrong $i s$ in treating the qualitative character of experience as if it were knowledge. Knowledge requires the use of concepts, to have a certain type of experlence does not. (of course identifying an experience as such-and-such type requires concepts). Similarly. to know a fact--even a fact of experience--requires the application and use of concepts. To know what it is like to be an $x$, then, only makes gense as a knowledge claim when we can conceptually and linguistically formulate propositions expressing that it 18 , indeed, like something to be an $x$. Understanding such propositions no doubt requires both the having of appropriate types of experiences and the understanding of appropriate types of concepts. This 18, In part, a vindication of physicalist or functionalist theories of mind. For once the dual nature of understanding mental concepts is understood and appreciated it can no longer be held that the exclusive 'mark' of the mental is privacy and 
incorrigibility. Public criteria must also be considered. Thus there should not be anything troublesome in the fact that science moves away from facts which are accessible from only one point of view and towards facts which are intersubjective and public: there are no facts which are accessible from only one point of view.

NOTES

"T. Nage1. "What is it Like to be a Bat?" Mortal Questions, (Cambridge: Cambridge University Press, 1979).

${ }^{2}$ For reference, see note 2 .

'T. Nagel. "What is it Like to be a Bat?" Mortal Questions, (Cambridge: Cambridge University Press, 1979).

'Saul Kripke, Wittgenstein: On Rules and Private Language, (Cambridge: Harvard University Press, 1982).

'Although I do not argue for it in this paper, I take functional states to be physical states which bear appropriate causal relations to other physical states. On this anslysis, what all pains have in common are causal relations to other states; however, any number of physical entities, states, or events may instantiate these relations. I take it to be a contingent fact about the world we live in that only physical entities (or states, or events) can instantiate these relations. This doctrine 18 sometimes referred to as 'token physicalism' and represents the weakest form of physicalism.

'R. Warner, "In Defense of a Dualism," p. 5

'Ibid., p. 7 .

Ibid., p. 9.

Ib1d.. p. 21.

2 Ib1d.. p. 9 .

"Ibid.., p. 13 .

'It might be thought that Warner's argument cannot imply Nagel's since, as I remarked earlier, Nagel's thesis is the stronger of the two. While Nagel's thesis concerning the limits of science is stronger than 
anything Warner assumes or argues for, Nagel's specific argument from properties of individual points of view to the limitations of physicalism is essentially Warner's argument. My point above was that if the argument from pain can be generalized to include all bodily and perceptual sensations, then Warner's argument implies Nagel's.

"For discussion of this and related topics, see Janet Levin's "Could Love Be Like A Heatwave? Materialism and the Subjectivity of Experience," unpublished.

"s. Kripke, Wittgenstein: On Rules and Private

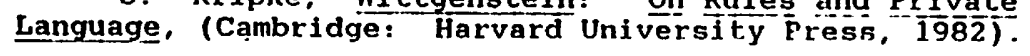

